\title{
CIDADANIA, IGUALDADE E DIFERENÇA
}

\section{ADRIÁN GURZA LAVALLE}

A expansão dos direitos civis no século XVIII, a emergência da vida pública e o assalariamento de crescentes camadas da população desencadearam, no longo prazo, processos pujantes de integração social. Esses processos operaram sobre a ruína e a desagregação social de formas arraigadas de pertença e filiação comunitária. A obra destrutiva da construção das sociedades modernas encetou, assim, a problemática da questão social enquanto expressão especificamente moderna da desigualdade. Entretanto, o processo simultâneo de ampliação do desarraigo, e de subordinação disciplinar da população aos ditames do mercado de trabalho, veio acompanhado de novas vias de integração: edificaram-se os expedientes modernos de constituição e vinculação a uma comunidade política regida por princípios universais e por mecanismos públicos de produção de legitimidade. A cidadania constituiu a cristalização institucional desses novos expedientes de solidariedade abstrata e generalizada.

A cidadania moderna, assim definida e ampliada secularmente mediante o reconhecimento de novos direitos e de novos setores da população investidos com capacidade legal de usufruí-los, encontra-se hoje diante de uma encruzilhada de caminhos incertos. As condições que lhe outorgaram viabilidade política e plausibilidade simbólica, enquanto status universal, sofreram transformações profundas; transformações cujas implicações suscitam controvérsia quanto ao futuro da própria cidadania e aos eventuais rumos de sua reconstrução para se adequar às exigências dos novos tempos.

As páginas que se seguem estão inscritas nesse cenário e nelas é desenvolvida uma análise i) da concepção tradicional da cidadania, ii) das forças responsáveis pela sua desestabilização, iii) das reações na literatura teórica perante tal desestabilização e, sobretudo, iv) das diferentes tensões 
que, na edificação da cidadania moderna, caracterizaram a relação do binômio igualdade/diferença - tensões tematizadas de forma parcial no debate contemporâneo. Por razões a serem analisadas no percurso deste texto, propõe-se que não existem, hoje, empecilhos de peso na lógica universalista da cidadania para a assimilação política e institucional dos reclamos da diferença; no entanto, nas últimas décadas têm se cristalizado sérias restrições à expansão da cidadania - especialmente no que diz respeito à capacidade do Estado para universalizar benefícios. Configurase assim um panorama que encerra certa ironia histórica: o reconhecimento da diferença, porém sem eqüidade.

\section{A CONCEPÇÃO TRADICIONAL E SUA CRÍTICA}

A primeira dificuldade ao se falar da "crise" ou desafios atuais da cidadania consiste no pressuposto da existência de um conjunto de traços razoavelmente consensuais, cuja conjugação define aquilo que deve ser compreendido por cidadania moderna, fornecendo assim um parâmetro de comparação para se avaliar a natureza e envergadura de determinadas transformações em curso. Falar em "cidadania moderna", nesse sentido, apenas é possível no plano de formulações em maior ou menor medida abstratas, cuja construção estilizada permite sintetizar para a análise aquilo que, no terreno da história, corresponde aos complexos processos de edificação dos Estados-nação; processos tanto mais diferenciados quanto mais se aproxima a análise da questão social — dos direitos sociais — e de sua cristalização em constelações distintas de regimes e bem-estar (EspingAndersen, 1991: 85-116; 1995: 73-111).

Sem dúvida, a concepção mais influente da cidadania moderna foi elaborada por T. H. Marshall, quando da sua conferência seminal "Cidadania e Classe Social", ministrada no final dos anos quarenta a propósito da obra do economista Alfred Marshall. A tal concepção seria pertinente adicionar as formulações de Reinhart Bendix — não apenas por sua influência, mas por se tratar de desenvolvimento analítico complementar ao pensamento do primeiro autor. No contexto da argumentação aqui apresentada, assume-se que a concepção tradicional da cidadania pode ser cabalmente encontrada no opúsculo canônico de Marshall (1949) ou no estudo clássico do segundo autor acerca da relação entre a cidadania e os processos de centralização do poder em aparatos burocráticos modernos construção do Estado-nação (Bendix, 1964). É claro que as idéias de 
ambos os sociólogos não são isentas de controvérsias; todavia, os matizes e restrições introduzidos pelas críticas mais recorrentes não comprometem o núcleo daquilo que ainda hoje é tido como as feições distintivas da cidadania moderna. È bem conhecido o modelo dito evolutivo de Marshall, no qual o progressivo alargamento da cidadania - enquanto status de direitos atribuídos - emerge como desdobramento dos direitos civis em políticos, e destes em direitos sociais; contudo, a excessiva atenção normalmente prestada ao componente dinâmico da concepção marshalliana tende a obliterar aquilo que de mais importante têm o pensamento desse autor quanto às características constitutivas da cidadania moderna. Groso modo, tais características são passíveis de síntese em quatro elementos ${ }^{1}$ :

i) universalidade da cidadania: atribuição de um status elaborado em termos de direitos universais para categorias sociais formalmente definidas, ao invés de para estamentos ou castas com qualidades substantivas inerentes;

ii) territorialização da cidadania: territorialidade combinada com o elemento anterior para delimitar politicamente os alcances da cidadania, ou seja, assunção do território como critério horizontal a delimitar a abrangência desse status, em substituição dos princípios corporativos;

iii) princípio plebiscitário da cidadania ou individualização da cidadania: generalização dos vínculos diretos entre o indivíduo e o Estado como forma legítima de reconhecimento e subordinação política, suprimindo não apenas o princípio funcional da tutela das antigas corporações, mas também o chamado governo indireto, quer dizer, a delegação das funções do Estado às camadas locais de intermediários entre os poderes centrais e os donos de terras, os mercenários, o clero, e diversos tipos de oligarquias;

iv) índole estatal-nacional da cidadania: existência de vínculo constitutivo entre a cidadania e a edificação do Estado-nação, graças à construção histórica de coincidência dupla: entre o território e um poder centralizado único, de um lado, e, do outro, entre a população constituída como comunidade política e o Estado enquanto encarnação presuntiva

$1 \mathrm{O}$ núcleo aqui proposto pode ser consultado de forma pormenorizada, com maior ou menor ênfase em algumas das feições expostas, nas seguintes páginas das obras em questão (Marshall, 1949: 63-108; Bendix, 1964: 91-138). Em trabalho alentado mais recente, Charles Tilly (1993: 157-93) também confere centralidade a esses elementos. 
dessa comunidade concebida em termos culturais ou de identidade nacional. ${ }^{2}$

Antes de sumariar as discrepâncias mais freqüentes suscitadas pela concepção tradicional da cidadania no debate das últimas décadas do século XX, cumpre atentar para um aspecto presente de forma implícita na conjugação dos elementos vertidos acima, cujas implicações adquirirão relevância no decorrer destas páginas. Na concepção tradicional da cidadania, não apenas como burilada analiticamente por Marshall ou Bendix, mas também tal e como incorporada pela teoria social no terceiro quartel do século XX, "cidadania" opera no plano cognitivo como conceito sintéticodescritivo e não como categoria normativa. Por outras palavras, os elementos recém-expostos pretendem fornecer uma síntese capaz de descrever os caminhos percorridos historicamente na edificação do status moderno da cidadania, sem assumir qualquer afirmação sobre a substância ou dever ser da cidadania.

O uso analítico do termo remete de forma sintética a processos longos e conflituosos de sedimentação de direitos civis, políticos e sociais, mediante os quais equacionaram-se nas sociedades ocidentais os dilemas da subordinação política e da integração social. Se em cada caso histórico os usos práticos - políticos e ideológicos — da idéia de cidadania englobam o valor da vida digna presente nessa sociedade, a reconstrução analítica do conceito, do ponto de vista da teoria social, não pressupõe a aceitação ou prescrição de qualquer conteúdo necessário à substância da cidadania. Para dizê-lo nas palavras de Marshall: "A cidadania é um status concedido àqueles que são membros integrais de uma comunidade. Todos aqueles que possuem o status são iguais com respeito aos direitos e obrigações pertinentes ao status. Não há nenhum princípio universal que determine o que estes direitos e obrigações serão, mas as sociedades nas quais a cidadania é uma instituição em desenvolvimento criam uma imagem de uma cidadania ideal em relação à qual o sucesso pode ser medido e em relação à qual a aspiração pode ser dirigida". (Marsahll, 1949: 76) Segundo será visto mais adiante, ante as forças desestabilizadoras da concepção tradicional da cidadania, re-

2 Para uma reconstrução geral desse vínculo e de sua importância para a cidadania (cf. Bendix, 1964: 91-175). Na América Latina, a construção e imposição históricas da coincidência entre Estado e Nação tem sido menos explorada do ponto de vista dos seus efeitos para a cidadania do que da perspectiva da história cultural ou intelectual desses países. A esse respeito cumpre lembrar a intensa participação do pensamento social da região na empreitada de inventariar e inventar a nação (cf. Bartra: 1987, pp, 43-125; Gurza Lavalle: 2001, pp. 132-246. Leite: 1968, pp. 15-132; Mota: 1977, pp. 17-52). 
gistra-se mudança notável de sentido nos usos conceptuais dessa categoria - agora investida de considerável carga normativa.

Uma vez explicitado o teor sintético-descritivo da concepção tradicional da cidadania, cabe dar passo de forma breve a suas críticas mais freqüentes. No último quartel do século XX, em particular após a ascensão do neoconservadorismo, a temática da cidadania passou a ser explorada de forma crescente, até assumir posição de destaque no debate acadêmico dos últimos anos - em especial na agenda da filosofia política e da teoria social. No corpus dessa literatura, em expansão vertiginosa, são bem conhecidas as críticas à concepção marshalliana, salientando de forma recorrente ora a indevida generalização do caso inglês, ora o desenho de roteiro histórico altamente estilizado quanto à gênese e transformação da cidadania, ora a simplificação da emergência dos direitos nas sociedades modernas em três subconjuntos indevidamente homogêneos, ora certo evolucionismo e linearidade em relação à trajetória efetivamente seguida pelas sociedades européias — inclusive a inglesa (cf. Miller, 1993: 72-8; Zolo, 1993: 119-121; Held, 1989: 41-65). Não é esta a oportunidade para avaliar a pertinência dessas ressalvas, apenas cabe explicitar que a despeito de sua ampla difusão, nem todas elas fazem juz ao pensamento do sociólogo britânico, particularmente se considerada a ausência de uma filosofia da história subjacente à sua análise, e, portanto, sua concepção da mudança social como fenômeno por excelência contingente (Held, 1997: 45-9).

Em perspectiva mais abrangente, o caráter liberal da concepção tradicional da cidadania foi questionado da ótica dos marxismos pela ausência de formulações quanto ao papel desse status sócio-político moderno dentro da lógica de dominação do Estado-nação, e pela escassa atenção prestada ao conflito social no reconhecimento de novos direitos (cf., v.gr. Giddens, 1985: 217-27). ${ }^{3}$ Embora o sentido geral dessas críticas seja parcialmente correto, elas ocultam que a verdadeira divergência reside em outro ponto, na centralidade conferida pelo marxismo à luta de classes, pois, embora em registro diferente, tanto as demandas coletivas na definição de novos direitos - e na ampliação dos já existentes — quanto o papel da cidadania na consolidação do Estado, constituem temas relevantes nas reflexões de ambos os autores. Para além da correção ou incorreção dessas e de outras críticas menos usuais, a síntese proposta por

3 No plano da ação individual, Marshall e Bendix — este último de forma mais explícita — frisam o desejo de pertença e reconhecimento das camadas populares como motores da ampliação da cidadania, enquanto Giddens acusa ambos os autores de se furtarem a enfrentar a questão da dominação e dos conflitos sociais na construção da cidadania. 
Marshall, assim como suas repercussões e reformulação na sociologia histórico-comparativa de Bendix, permanecem ainda hoje como pontos de referência obrigatórios no debate acerca do futuro da cidadania.

\section{AS FORÇAS DESESTABILIZADORAS}

É possível delinear certos consensos no plano da "crise" da cidadania ou, melhor, das tendências que, em tese, abalariam alguns de seus pressupostos modernos de funcionamento. É amplamente aceito que a expansão desse status universal de pertença a uma comunidade política forneceu os expedientes predominantes para equacionar, nos planos simbólico e político-institucional, as problemáticas da subordinação política e da integração social ao longo dos processos seculares de alastramento da economia de mercado e de consolidação do Estado nacional. Mesmo em sociedades marcadas por diferenças socioeconômicas abissais, pela desigual efetivação do direito, pela vulnerabilidade dos direitos civis e por outras iniqüidades amplamente presentes na América Latina, as tarefas da ordenação política e da incorporação social passaram pela edificação da cidadania - embora não raro sob formas qualificadas com adjetivos que visam a acusar alguma anomalia (cf. Escalante Gonzalbo, 1992; Santos, 1979; Telles, 1992; Fleury, 1994). Para além das polêmicas em torno da (in)suficiência e (in)eficiência da cidadania, os modelos ideais e arranjos institucionais que, no século XX, definiram seu notável alargamento quanto à cobertura e à substância, parecem hoje comprometidos por tendências de médio e longo prazos. ${ }^{4}$

Cumpre centrar a atenção, primeiro, nas forças desestabilizadoras da cidadania no terreno dos pressupostos macroinstitucionais ou estatais que viabilizaram politicamente sua consolidação. Trata-se, é claro, da capacidade do Estado para institucionalizar volumes conflitantes de interesses populares, e para impor as decisões vinculantes - inclusive a assunção de perdas - exigidas por tal institucionalização. Hoje, uma combinação complexa de fatores exige com premência a ação pública e, a um só tempo, limitam sua efetividade e seus alcances. A vulnerabilidade finan-

4 A substância da cidadania corresponde, em Marshall, aos componentes do bem-estar que, formando parte do seu patrimônio cultural e material, cada comunidade julga indispensáveis para garantir uma vida digna; por sua vez, a cobertura remete ao aspecto quantitativo ou numérico, quer dizer, às regras formais a delimitarem os segmentos sociais contemplados pela cidadania. 
ceira e migratória das fronteiras nacionais, os processos de integração econômica internacional e a conseqüente cessão parcial de soberania, o acirramento da desigualdade social sob formas inéditas — entre elas o alastramento do desemprego estrutural —, a redefinição do papel do Estado e sua conseqüente retração no plano da intervenção social, adicionada às crescentes limitações fiscais da ação pública, compõem um panorama crivado de restrições não apenas para a ampliação da cidadania, senão também para preservação de sua substância já cristalizada em direitos. Mais adiante serão retomadas de modo breve essas forças enquanto constrangimentos à efetiva capacidade de universalização da cidadania, paradoxalmente, em momento simbolizado pelo crescente reconhecimento do direito à diferença.

Já o segundo conjunto de fatores presentes na desestabilização da cidadania diz respeito à diferenciação social e a mudanças socioculturais. Trata-se, em grandes traços, de fenômenos os mais diversos a exprimirem de formas distintas as dificuldades de se representar e processar, com plausibilidade simbólica, questões outrora elaboradas na linguagem do universal: o descrédito das grandes ideologias, a suspeição suscitada pelas categorias totalizadoras (Savater, 1989), a emergência e proliferação de identidades restritas (Zermeño, 1987), o desencanto da política (Tenzer, 1990), a multiplicação de formas associativas civis a reivindicarem novos princípios de representatividade (Dagnino, 2002), a proliferação da chamada política da diferença, entre outras manifestações.

Nesse elenco há fenômenos em maior ou menor medida recentes, mas sem dúvida a eles também subjazem tendências que obedecem linhas de mudança de longa duração. De fato, pluralismo, política da diferença, diferenciação social, evolução e incremento da complexidade social, especialização funcional, multiplicação dos sentidos socialmente relevantes, descentramento da sociedade, nomadismo das identidades, constelações pós-nacionais e patriotismo constitucional são, entre outros, termos de uso crescente nas ciências sociais ao longo da segunda metade do século XX, e, malgrado as controvérsias e até os dissensos irreconciliáveis entre aqueles que os sustentam, em conjunto coincidem em ponto crucial, a saber, que não mais é plausível responder aos problemas do ordenamento político e da integração social como fizeram-no os pensadores oitocentistas; quer dizer, a partir dos pressupostos e categorias ilustrados de teor fortemente universalista, próprios à cidadania moderna.

As conseqüências desses fenômenos para a concepção tradicional da cidadania nem sempre são evidentes e, sobretudo, raras vezes são 
unívocas. À guisa de ilustração cabe analisar como mudanças acontecidas no plano difuso da ação social e das identidades coletivas poderiam acarretar efeitos corrosivos para o funcionamento da cidadania. Considerações de longo e curto prazos são invocadas freqüentemente na literatura para explicar a emergência e proliferação inédita de uma miríade de práticas de consociação e atores coletivos orientados por identidades restringidas para dizê-lo com atinada fórmula cunhada por Sergio Zermeño (1987). Quando projetadas para a arena política, tais identidades geram efeitos desestabilizadores em dois flancos, na medida em que colocam em xeque, pelo menos parcialmente, duas ordens de pressupostos funcionais e simbólicos da concepção tradicional da cidadania: primeiro, a legitimidade da produção dos direitos que alteram o perfil da própria cidadania, seja como incorporação a enriquecer sua substância, seja como limitação restritiva ou reguladora dessa substância; segundo, o princípio de universalidade como critério normativo sine qua non a determinar o tipo de demandas, benefícios e obrigações passíveis de incorporação legítima no status da cidadania.

Assim, quanto à legitimidade dos processos consagrados de produção da cidadania, a diversificação de temas, interesses e problemas com pretensões semelhantes de validez e relevância — impulsionada pela proliferação de identidades restringidas —, tem evidenciado a parcialidade e insuficiência do arcabouço institucional incumbido da agregação e representação de interesses. Sem negligenciar o papel dos conflitos sociais não normalizados, é precisamente no interior das instituições da democracia que ocorrem os processos de determinação de prioridades na criação e regulação de direitos associados ao status de cidadão. Por sua vez, tais identidades firmam-se como portadoras de necessidades específicas e de reclamos diferenciados, cuja satisfação não é passível de equacionamento nos marcos de um status universal caracterizado desde suas origens por pressupostos normativos que alicerçaram simbolicamente o reconhecimento de direitos iguais para os membros da comunidade política em detrimento do direito à diferença. Em suma, em ambos os casos está em jogo a imparcialidade e representatividade dos processos institucionais de produção da cidadania, assim como sua sensibilidade para contornar os riscos da sinonímia entre igualdade e homogeneidade.

Especificamente no que diz respeito à igualdade, cabe lembrar que o quid reside no fato de a cidadania ter introduzido distinção dupla, de inclusão e exclusão: primeiro, expandiu o terreno da igualdade garantido pela lei, isto é, determinou áreas relevantes da vida social nas quais deviam primar condições de acesso, participação ou usufruto semelhantes para 
os segmentos sociais investidos de status cidadão; segundo, a consagração dessas áreas - da herança social a ser compartilhada como pressuposto de uma vida civilizada - simultaneamente desautoriza a legitimidade de qualquer demanda que escape de suas fronteiras. Nas palavras de Marshall: "O status não foi eliminado do sistema social. O status diferencial, associado com classe, função e família, foi substituído pelo status uniforme de cidadania que ofereceu o fundamento da igualdade sobre a qual a estrutura da desigualdade foi edificada". (1949: 79-80)

\section{AS REAÇÕES DIANTE DA DESESTABILIZAÇÃO}

A despeito dos diagnósticos oitocentistas, enfáticos na afirmação de duas classes de riscos próprios às tendências de transformação da cidadania, a desestabilização, esboçada de forma grosseira acima, não decorre do descompasso entre os anseios de integração e mobilidade social das camadas populares e o ritmo vagaroso do alargamento da cidadania insuficiências de número e substância na sua expansão -, e sequer dos efeitos politicamente explosivos acarretados por tal ampliação - efeitos deletérios para o funcionamento da democracia ou, nas hipóteses mais ousadas, eventuais consequiências revolucionárias —; antes, trata-se de processos em boa medida inéditos, particularmente se olhados da perspectiva desses diagnósticos. ${ }^{5}$

Conforme recém-exposto, confluem na redefinição da cidadania diversos fenômenos passíveis de serem aglutinados sinteticamente em processos de duas ordens, a saber, aqueles relacionados à dificuldade contemporânea de se processar a representação e resolução política de questões relevantes dentro de semânticas do universal; e aqueles que, vinculados à fragilização da soberania nacional e à redefinição dos padrões de intervenção do Estado, comprometem os fundamentos político-institucionais presentes na edificação da cidadania moderna. Os eventuais efeitos

\footnotetext{
5 A esse respeito cabe lembrar que a erosão das formas tradicionais de autoridade, e sua correspondente substituição por relações contratuais, veio acompanhada de acirrados debates em torno das conseqüências da desresponsabilização dos proprietários pela sorte dos seus empregados - agora indivíduos "liberados" das formas de proteção tutelares e comunitárias (cf. Bendix, 1964: 92-108). Vejam-se, também, as reações suscitadas pelo progressivo reconhecimento do direito de barganha coletiva do trabalhador, cuja sanção definitiva aconteceu como exigência compreendida no exercício dos direitos civis e não como desdobramento dos direitos políticos (cf. Marshall, 1949: 63-87).
} 
corrosivos de tais processos apontam para a impossibilidade de se enfrentar os novos desafios da integração social, nas suas dimensões simbólica ou identitária e socioeconômica, tentando equacioná-los analiticamente dentro dos moldes da concepção tradicional da cidadania; concepção cristalizada, não à ventura, no segundo pós-guerra enquanto expressão e explicação do "desdobramento" dos direitos sociais.

Ante tal cenário, e a partir de filiações teóricas e disciplinares diversas, há duas posições de confluência no debate acadêmico dos últimos anos que interessa destacar. No plano da emergência das singularidades como reclamos políticos legítimos, ou seja, dos avanços da política da diferença - para dizê-lo com fórmula cunhada recentemente, mas bastante difundida - tornou-se operação comum denunciar os excessos do universalismo da cidadania como categoria sociopolítica moderna, atentando para a problemática de sua (in)adequação às complexas dinâmicas da diferenciação cultural contemporânea. Já no plano das consequiências da reforma do Estado, da globalização, do neoliberalismo, da mundialização, ou outras etiquetas criadas para denominar os profundos processos de ajuste estrutural das últimas décadas, além da elaboração de diagnósticos acerca de como equacionar os efeitos negativos de tais processos, a cidadania tem sido reconstruída conceptualmente e promovida ao estatuto de categoria normativa da filosofia política e da teoria social. ${ }^{6}$ Enquanto no primeiro caso atenta-se para as conseqüências dissolventes de grandes tendências socioculturais sobre os pressupostos universalizantes e pouco diferenciados da concepção tradicional da cidadania (cf., v. g., Rosanvallon, 1995: 49-61), no segundo a ênfase recai na centralidade da própria cidadania enquanto categoria normativa capaz de alicerçar em novos termos a complexa problemática da solidariedade social (cf., v.g., Santos, 1995: 235-48; Dagnino, 1994: 103-15).

A segunda confluência é particularmente sintomática tanto dos desafios enfrentados pela cidadania quanto dos limites da concepção tradicional para equacionar tais desafios. Malgrado sua participação primordial na decantação da ordem social e política do Estado-nação, a cidadania não ocupou uma posição equivalente no debate teórico e, durante parte considerável do século XX, foi tida como um conceito "ultrapassado" e sem retornos analíticos de interesse. Com efeito, para dizê-lo com Kymlicka e Norman (1994: 23-330), os conceitos normativos fundamentais da teoria e

6 No que diz respeito a essa dupla confluência veja-se o cuidadoso balanço da literatura realizado por Kymlicka e Norman (1994: 5-39). 
da filosofia políticas do segundo pós-guerra foram democracia e justiça; isto é, as diversas problemáticas associadas às decisões políticas e aos critérios para avaliá-las e orientá-las em termos de resultados. Nesse sentido, a cidadania constituía apenas um atributo pressuposto que permitia situar os sujeitos como membros de uma comunidade auto-regulada por valores e mecanismos democráticos, e, por conseguinte, como portadores de reivindicações legítimas quanto aos benefícios e garantias inerentes à pertença a essa comunidade. Por sua vez, a teoria sociológica tampouco conferiu à cidadania uma posição teórica de destaque, incorporando-a aos estudos da área enquanto categoria histórico-descritiva ou, com maior precisão, enquanto denominação de um estatuto de pertença alicerçado em direitos.

A notável centralidade ganha pela cidadania no debate teórico e político das últimas décadas do século XX tem ocorrido alargando o perfil semântico dessa categoria para além de sua compreensão como atributo ou como mero estatuto jurídico. O componente jurídico-institucional permanece; todavia, sua compreensão sintético-descritiva é pressuposta e subordinada a uma nova ênfase normativa, no marco da qual tornam-se evidentes novos problemas: a disputa intelectual e política entre as linguagens da solidariedade e das obrigações, a redefinição do sentido e alcances funcionais da cidadania e, é claro, o debate pela resignificação do lócus político das exigências e reclamos normativos nas sociedades contemporâneas.

Essas mudanças na construção do significado da cidadania merecem estudo pormenorizado, todavia, é possível arrolar aqui alguns fatores relevantes na compreensão desse deslocamento para o plano normativo: a consolidação do discurso da cidadania como novo terreno comum de disputa entre a direita e a esquerda — obrigações versus solidariedade —; a chamada crise da política, a normalização de uma concepção restrita da democracia e, como resposta, a reinvenção de uma chave para reintroduzir no debate a "necessidade" das virtudes cívicas - comprometimento fora dos espaços tradicionais da política —; as consequiências das últimas décadas de ajustes estruturais na efetivação dos direitos sociais, o que implicou não apenas a emergência de uma linguagem defensiva em face do retorno dos argumentos acerca da inevitabilidade da exclusão, mas o desenvolvimento de idéias para defender a participação nas sociedades democráticas sob outros termos que não os do Estado de bem-estar; e o progressivo abandono de matrizes explicativas nos moldes marxistas. Em suma, sabe-se que o fim dos "trinta anos gloriosos" do pósguerra levou de roldão os consensos sobre o valor social da (des)igualdade e sobre os melhores mecanismos institucionais para equacioná-la; a dispu- 
ta pela definição de novos consensos explica em boa medida o auge da cidadania como categoria normativa no debate acadêmico e político dos últimos anos.

\section{REPENSANDO A IGUALDADE E A DIFERENÇA}

A dupla confluência acima esboçada apresenta alguns traços paradoxais. Como será argumentado logo a seguir, se, de um lado, a ênfase analítica nas implicações atuais da oposição universalismo ou igualdade versus diferença parecem supervalorizadas na literatura — particularmente se considerado que a tensão entre igualdade e diferença não mais se encontra subordinada ás exigências impostas pela construção dos Estados-nação —, do outro, a aposta na reconstrução da cidadania como categoria normativa, em contexto particularmente restritivo para a ampliação efetiva de direitos sociais, emerge como uma escolha analítica impregnada da força do apelo moral, mas com dúbios ganhos cognitivos para os desafios da análise social.

O espinhoso tema da relação entre igualdade e diferença impregna mas transborda a questão da cidadania, trazendo à tona os fundamentos da filosofia política e da teoria social modernas, pelo menos no sentido de a conexão entre ambos os termos evocar problemáticas clássicas no âmbito dessas áreas do conhecimento especulativo. No caso da filosofia política, trata-se da tensão entre a liberdade e a igualdade, de cujo cerne emergiram e continuam a emergir respostas acerca da desigualdade legítima; quer dizer, das desigualdades toleradas e inclusive consideradas necessárias à plena realização do homem e à reprodução da sociedade. Uma cristalização particularmente nítida dessa problemática reside na preponderância dos direitos negativos no pensamento liberal clássico. No campo da teoria social, a tensão entre igualdade e diferença remete ao binômio integração/ desintegração social, à questão social tal e como inaugurada pela modernidade (Castel, 1995); onde a ênfase no pólo da integração, característica da dimensão nacional dos Estados modernos, vem acompanhada da determinação de diferenças legítimas - aquelas que não comprometem a homogeneidade (pressu)posta pelas ideologias nacionais, nem ferem os estereótipos morais da vida social. Nesse sentido, cumpre lembrar, a cidadania operou como reconhecimento de diferenças legítimas incorporadas a sistemas institucionalizados e abstratos de solidariedade social. 
Aquém ou além dos obstáculos enfrentados pela teoria social e pela filosofia política na formulação de respostas capazes de conciliar tensões complexas como as recém-citadas - igualdade/liberdade, diferença/integração — é é fato que a evolução da cidadania permitiu aprimorar em escala nacional fórmulas de equacionamento simbólico e institucional do binômio igualdade/diferença. A despeito de essa afirmação ser pacífica ou isenta de controvérsia, a compreensão das tensões entre ambos os termos desse binômio na cidadania moderna é questão polêmica e complexa. De fato, a pertinência da crítica à concepção tradicional da cidadania por seu hermetismo perante a diferença atinge de forma algo imprecisa características constitutivas da cidadania que, todavia, não mais exercem papel central no seu funcionamento contemporâneo. Com maior precisão, a oposição entre igualdade e diferença pressuposta nessa crítica resulta extemporânea à própria concepção tradicional da cidadania, pois negligencia o fato de a igualdade assumir, a um só tempo e com sentidos diferentes, a posição de pólo contrário em mais de uma dicotomia central na configuração da própria cidadania.

Quando posta em oposição ao princípio da liberdade, concebido em chave liberal, a igualdade ocupou posição francamente subordinada, como atestado pelo fato de os direitos civis terem constituído a substância inicial da cidadania e de os direitos políticos terem emergido como desdobramento ideológico "natural" da capacidade civil da propriedade privada, isto é, da atribuição, aos livre-proprietários, do direito de participar na determinação dos rumos da comunidade política.

Quando situada no processo de definição da substância e cobertura da cidadania, a igualdade aparece vinculada a tensões diferentes, mas desta vez como pólo dominante perante a desigualdade e a diferença. Com efeito, a igualdade, com seu potencial integrador, consagrou-se como registro dominante para lidar simultaneamente com a desigualdade e com a diferença; todavia, no primeiro caso o significado antônimo apontava para a equalização e no segundo para a homogeneização — integração material e cultural ou identitária, respectivamente. Nessa perspectiva, a igualdade opera como idéia extraordinariamente potente para equacionar em registros distintos tanto a questão da desigualdade quanto a questão da diferença: a primeira concebida no plano das disparidades socioeconômicas, das condições a perpetuarem o acesso desigual aos recursos materiais; a segunda entendida no terreno da atribuição do status da cidadania, da delimitação do conjunto de iguais que formam a comunidade política, isto é, da identidade. 
Embora nem sempre diferenciados com nitidez no debate dos últimos anos, há, com efeito, dois eixos em que operam dinâmicas de igualdade na cidadania moderna; ambos inscritos em tendências que levaram à progressiva aceitação de critérios universais para a especificação da cobertura e substância desse status. No que diz respeito à substância da cidadania, ou seja, à determinação das desigualdades que não podem ser admitidas em determinada comunidade política, os componentes de bem-estar adequados a uma vida digna foram processados mediante a tríade "desigualdade/ integração socioeconômica/ equalização" ordenada na sequiência problema, meio e fim. Se os efeitos de equalização são inerentes à expansão da cidadania moderna, seus alcances, é claro, derivaram de processos históricos particulares em que se conjugaram, entre diferentes fatores, lutas sociais e políticas, tradições culturais, e estruturas socioeconômicas.

No limite, os processos de equalização social se alastraram de forma tão intensa a partir da segunda metade do século XIX, e, sobretudo, no século XX, que Marshall concluiu pelo efetivo abrandamento da classe social enquanto sistema de desigualdades. Mais: mesmo considerando que a expansão da cidadania assentava as bases de novas formas de desigualdade legítima, em princípio não parecia existir qualquer limite necessário — identificável a priori — para tal expansão. Em bela passagem do seu opúsculo, discorrendo sobre a eventual diminuição da ambição social de mobilidade socioeconômica sob os influxos equalizadores dos direitos sociais, o autor realiza afirmação bastante ilustrativa: "Se isto se desenvolver em demasia, poderemos verificar que a única motivação restante com um efeito distributivo consistente [...] será a ambição do menino de fazer seus deveres escolares, passar nos exames e ser promovido na escala educacional".(1949: 108)

Quanto à determinação da cobertura da cidadania, a igualdade remete ao plano da identidade, da delimitação da comunidade política de iguais á qual poderá ser atribuído o status. Nesse caso, a construção simbólica e política da comunidade nacional ou, melhor, a nacionalização de uma comunidade inventada, com a conseqüente delimitação da categoria "estrangeiro", foi atendida mediante a tríade diferença/ integração políticocultural/ homogeneização - também conforme à seqüência problema, meio e fim. Sabe-se que, em percurso secular, a cidadania tornou-se expressão de um status de direitos universais para os membros de determinada comunidade política, mas também, e isso é fundamental, alicerçou a própria consolidação do Estado-nação. Se o nexo entre direitos e status, 
consagrado na cidadania moderna, assimilou longa tradição medieval de atribuição estamental de direitos - consoante com uma concepção da cidadania ancorada no princípio da personalidade ${ }^{7}$ — , sua "territorialização" constitui nota distintiva especificamente moderna. O caráter territorial da cidadania exprime seu desenvolvimento enquanto fenômeno paralelo à concentração do poder e à construção histórica da soberania estatal como princípio de autoridade inconteste dentro das fronteiras nacionais.

Assim, a cidadania tornou-se fulcro da articulação entre legitimidade, identidade e a integração social. ${ }^{8}$ À margem da violência amplamente exercida para construir a identidade entre o Estado e a nação, não há duvida quanto ao papel desempenhado pelo progressivo alargamento da cidadania como pedra angular que viabilizou o vínculo entre subordinação e incorporação nas sociedades modernas. Por isso a ambigüidade ou o caráter duplo da cidadania: de um lado, em decorrência dos conflitos sociais e do imperativo da integração, seu extraordinário vigor como instrumento de redução da desigualdade; do outro, em conexão com as exigências do domínio, seu papel na homogeneização forçada de qualquer diferença não equacionável em termos de "legítima" igualdade universal notadamente, a supressão simbólica e até existencial de todas aquelas qualidades consideradas estranhas aos atributos "fundadores" da identidade nacional (raça, língua, religião, linhagem etc) (Lomnitz, 2001: 37-61; Tilly, 1992: 161-71).

A homogeneização fundamental introduzida pela cidadania é, pois, produto e condição de possibilidade da edificação do Estado-nação. É claro que ao se privilegiar o cidadão como categoria formal e, portanto, impessoal para a atribuição de direitos, diferenças como as de gênero, cultura, ou preferência sexual (para considerar distinções mais atuais), efeti-

7 Personalidade desprovida de quaisquer conotações subjetivas ou psicológicas — por sinal, introduzidas pelo romantismo e ainda hoje dominantes - ; antes, personalidade no sentido histórico-sociológico, enquanto atributos objetivos vinculados à pessoa, Trata-se, nesse sentido, de uma cidadania centrada no princípio da personalidade (Brinkmann: 1965). Cumpre lembrar que a tal concepção da cidadania também correspondeu uma configuração de status ou representativa da publicidade (Öffentlichkeit) (cf. Habermas: 1962; Gurza Lavalle: 1998). 8 Seja dito de passagem, a própria fórmula "Estado-nação" é extraordinariamente sintética: introduz o pressuposto, por sinal anacrônico, da coincidência "natural" entre o Estado enquanto domínio político sobre um determinado território, e a nação como identidade ou unidade primigênia - da qual o primeiro seria, a um só tempo, expressão fiel e salvaguarda de integridade. Por outras palavras, o nexo entre a ordem política — Estado - e a integração social em grande escala — nação — aparece como condição de legitimidade do próprio Estado. 
vamente ativas na vida das comunidades, foram parcial ou totalmente escamoteadas no estabelecimento dos padrões de convivência aceitos como civilizados e legítimos. Daí as faces positiva e negativa da igualdade na cidadania, no primeiro caso como afirmação de padrões satisfatórios de bem-estar para uma vida digna, e no segundo como supressão da diferença.

Porém, o desafio histórico da edificação dos Estados e das soberanias nacionais foi superado, em piores ou melhores termos, pela maior parte das sociedades ocidentais ao longo dos últimos três séculos na América Latina só um século depois das guerras de independência. ${ }^{9}$ Não mais há imperativos de supressão da diferença como condição de estabilização do próprio Estado; antes, é a plena consolidação do Estado que parece ter aberto as portas para renegociar em novos termos a questão da diferença. Com efeito, mais do que uma contradição entre os reclamos da diferença e os princípios universais de uma cidadania formal, observam-se hoje inúmeras experiências de adequação institucional dessa categoria às exigências dos novos tempos. Diferentemente da rigidez apontada na literatura, a cidadania tem mostrado extraordinária flexibilidade na incorporação de formas não tradicionais de representação de interesses e na ampliação de sua substância mediante o reconhecimento de direitos específicos; flexibilidade, aliás, evidenciada há tempo com a admissão de direitos sociais de índole corporativa, destacados por Marshall e por Bendix como uma anomalia na lógica interna do desenvolvimento da cidadania. Dentre outros, são exemplos dessa maleabilidade a expansão de políticas públicas afirmativas, a multiplicação de formas participativas no exercício da administração do Estado, o reconhecimento generalizado do voto no exterior e o reconhecimento de autonomias intranacionais.

Nesse sentido, não parece descabido afirmar que a conciliação prática entre igualdade e diferença está longe de representar obstáculo incontornável nas tendências atuais da cidadania. Não parece provir daí da universalização processada sob condições de heterogeneidade - o maior desafio a ser enfrentado por essa categoria política moderna, mas da corrosão das condições para operar uma efetiva universalização da eqüidade. Trata-se do primeiro conjunto de forças desestabilizadoras da concepção tradicional da cidadania já abordado, isto é, da desestruturação dos pressupostos macroinstitucionais ou estatais que viabilizaram politica-

9 Não é o caso, é claro, de paises que ainda estão às voltas com a consolidação de ordens políticas nacionais, como acontece na África, ou cuja recente fragmentação esteve marcada pela etnização dos conflitos, como ocorre nos Bálcãs. 
mente a ampliação efetiva desse status. Constrangimentos de diversa índole têm reduzido a capacidade do Estado para absorver demandas e investi-las de estatuto público na forma de direitos. Na questão é fácil reconhecer um componente de restrições materiais ou econômicas a diminuir o leque de demandas sociais passíveis de serem atendidas, o que levanta o paradoxo de uma crescente heterogeneização da substância da cidadania sem condições institucionais correspondentes que viabilizem politicamente sua efetivação.

Porém, há nesses constrangimentos à ação pública um componente simbólico menos evidente, cujas consequiências merecem atenção. Trata-se do abandono da semântica política no discurso do Estado e da sua substituição por uma linguagem cifrada em termos econômicos. Particularmente do ponto de vista fiscal, não é banal lembrar que a consolidação da cidadania como sistema abstrato de solidariedades constitui um dos feitos mais extraordinários a possibilitarem a integração nas sociedades modernas. A progressiva abstração da cidadania ocorreu de forma paralela ao advento dos impostos, quer dizer, à história da substituição dos expedientes de tributação negociados em espécie com o Estado em troca de concessões específicas (Tilly, 1992: 161-66). Assim, a existência de benefícios locais, pactuados pela aceitação de deveres perante o Estado - como o recrutamento militar de um filho por família, ou o sacrifício de parcela da produção familiar — , cedeu passo paulatinamente ante as noções abstratas de direitos universais e do imposto como nexo tributário desvinculado de benefícios concretos (Brinkman, 1965: 471-2). Para além dos constrangimentos orçamentários, sem dúvida fundamentais, a atual linguagem do Estado mina as condições simbólicas da sua atuação no sentido de ampliar ou mesmo apenas de assegurar a substância da cidadania. Lançando mão de frase de efeito, o panorama até aqui esboçado poderia ser sintetizado em fórmula que encerra certa ironia histórica: diferença sem eqüidade, quer dizer, a diversificação da substância da cidadania — reconhecimento dos reclamos da diferença — sem condições para avançar na universalização da eqüidade.

\section{À GUISA DE CONCLUSÃO}

Há mais de uma década vêm se avultando indícios do descompasso entre a concepção tradicional da cidadania e a capacidade do Estado para promover a eqüidade e para garantir a universalidade de diretos já cristalizados, ou, para dizê-lo em termos mais drásticos, velhos consensos 
sobre o valor da (des)igualdade esvaíram-se e a própria definição da idéia de cidadania tornou-se, pela primeira vez, objeto de disputa normativa no campo do debate acadêmico. Talvez uma questão relevante para a qual caberia atentar é o fato de a entronização da cidadania como categoria nevrálgica do debate político e teórico nos últimos anos responder tanto à presença de forças desestabilizadoras da concepção tradicional quanto a uma disputa ainda incerta pela redefinição de seus contornos e novos conteúdos substantivos; disputa, aliás, protagonizada por atores políticos, estatais e sociais com orientações ideológicas diferentes.

Mais ainda, parece pertinente afirmar que a resignificação da cidadania exprime de forma emblemática os desafios do presente: de um lado, seu alargamento conceitual aponta para a necessidade de redefinir os termos da convivência nas sociedades democráticas; do outro, sua "inflação normativa" — para dizê-lo com Danilo Zolo (1993: 122) — evidencia a ausência de respostas e de alternativas de encaminhamento material. Em boa medida continuamos a pensar dentro das balizas construídas pelos séculos das luzes e, por certo, não à ventura: em parte, talvez, porque esse marco de referência oferece certezas; em parte, quiçá, porque ainda não encontramos ou desenvolvemos respostas satisfatórias; mas, sobretudo, porque, para além das acomodações práticas possibilitadas pela surpreendente flexibilidade da cidadania, o desafio enorme reside em encontrar novos modelos que possibilitem não apenas preservar defensivamente a eqüidade, mas ampliá-la com efetividade universal sem abrir mão da diferença.

ADRIÁN GURZA LAVALLE é pesquisador do Centro Brasileiro de Análise e Planejamento (Cebrap) e professor do Departamento de Política da Pontifícia Universidade de São Paulo (PUC-SP).

\section{REFERÊNCIAS BIBLIOGRÁFICAS}

BARTRA, Roger (1987). La jaula de la melancolía — Identidad y metamorfosis del Mexicano. México, Grijalbo, 1996.

BENDIX, Reinhard (1964). Construção nacional e cidadania. São Paulo, Edusp, 1996.

BIRNKMANN, Carl. "Citizenship". Encyclopedia of the social sciences. Inglaterra, 1965.

CASTEL, Robert (1995). Las metamorfosis de la cuestión social — Una crónica del salariado. Buenos Aires, Paidós, 1997.

DAGNINO, Evelina. "Os movimentos sociais e a emergência de uma nova noção de cidadania". In _ (org.). Anos 90: Política e sociedade no Brasil. São Paulo, Brasiliense, 1994, pp. 103-15.

"Sociedade civil, espaços públicos e a construção democrática no Brasil: 
limites e possibilidades. In (org.). Sociedade civil e espaços públicos no Brasil. São Paulo, Paz e Terra, 2002, pp. 279-301.

ESCALANTE GONZALBO, Fernando. Ciudadanos imaginarios. Memorial de los afanes y desventuras de la virtud y apología del vicio triunfante en la República Mexicana - Tratado de moral pública. México, Colmex, 1992.

ESPING-ANDERSEN, Gosta. "As três economias políticas do welfare state". Lua Nova, no 24, CEDEC, setembro de 1991, pp. 85-116.

FLEURY, Sônia. Estado sem cidadãos - Seguridade social na América Latina. Rio de Janeiro, Editora Fiocruz, 1994.

GIDDENS, Anthony (1985). O Estado-nação e a violência - Segundo volume de uma crítica contemporânea ao materialismo histórico. São Paulo, Edusp, 2001.

GURZA LAVALlE, Adrián. Espaço e vida Públicos: Reflexões teóricas e sobre o pensamento político social no Brasil. 2001, Tese de doutoramento apresentada junto ao DCP-FFLCH/USP, 2001.

Estado, sociedad y medios —Reivindicación de lo público. México, Plaza y Valdés Editores/ UIA, 1998.

HABERMAS, Jürgen (1962). Historia y Crítica de la opinión pública — La transformación estructural de la vida pública. México, Gustavo Gili, 1994.

HELD, David (1989). "Ciudadanía y autonomía”. La Política, no. 3, Ciudadanía. El debate contemporáneo. Barcelona, Paidós, 1997, pp. 41-67.

KYMLICKA, Will e NORMAN, Wayne (1994). "El retorno del ciudadano. Una revisión de la producción reciente en teoría de la ciudadanía". La Política, no. 3: Ciudadanía. El debate contemporáneo. Barcelona, Paidós, 1997, pp. 5-39.

JONES, Emma e GAVENTA, John. Concepts of citizenship: a review. Sussex, Institute of Development Studies, 2002, pp. 1-35.

LEITE, Dante Moreira (1968). O caráter nacional brasileiro - História de uma ideologia.

LOMNITZ, Cláudio. "O nacionalismo como sistema prático — A teoria de Benedict Anderson da perspectiva da América Hispânica". Novos Estudos, no. 59, CEBRAP, março 2001, pp. 37-61.

MARSHALL, T. H. (1949). Cidadania, classe social e status. Rio de Janeiro, Zahar 1967.

MILLER, David (1993). "Ciudadanía y pluralismo”. La Política, no. 3: Ciudadanía. El debate contemporáneo. Barcelona, Paidós, 1997, pp. 69-92

MOTA, C. G. Ideologia da cultura brasileira (1933-1974). São Paulo, 1977.

ROSANVALLON, Pierre. La nueva cuestión social — Repensar el Estado providencia. Buenos Aires, Manantial, 1995.

SANTOS, Boaventura Sousa de (1995). Pela mão de Alice - O social e político na pós-modernidade. São Paulo, Cortez, 1997.

SANTOS, Wanderley Guilherme dos. Cidadania e justiça - A política social na ordem brasileira. Rio de Janeiro, Editora Campus LTDA, 1979.

SAVATER, Fernando. Panfleto contra el todo. Madrí, Alianza Editorial, 1989.

"O futuro do welfare state na nova ordem mundial". Lua Nova, no. 35, CEDEC, 1995, pp. 73-111.

TELLES, Vera da Silva. A cidadania inexistente: incivilidade e pobreza - Um estudo sobre o trabalho e a família na Grande São Paulo. Tese de doutoramento apresentada junto ao DS-FFLCH/USP, 1992.

TENZER, Nicolas (1990). La sociedad despolitizada — Ensayo sobre los fundamentos da política. Barcelona, Paidos.

TILLY, Charles (1993). Coerção, capital e Estados europeus. São Paulo, Edusp, 1996.

ZERMEÑO, Sergio. "Hacia una democracia como identidad restringida: sociedad y política en México". Revista Mexicana de Sociología, no 2, IIS-UNAM, 1987.

ZOLO, Danilo (1993). "La ciudadanía en una era poscomunista". La política, no 3: Ciudadanía —El debate contemporáneo, pp. 117-31. 


\section{RESUMOS/ABSTRACTS}

\section{CIDADANIA, IGUALDADE E DIFERENÇA}

ADRIÁN GURZA LAVALLE

$\mathrm{O}$ artigo atenta para um aspecto específico das tendências recentes de transformação da cidadania: o avanço do reconhecimento da diferença combinado com forte regressão no plano da eqüidade. Para tanto, desenvolve-se uma análise da concepção tradicional da cidadania, das forças responsáveis pela sua desestabilização, das reações na literatura teórica perante tal desestabilização e, sobretudo, das diferentes tensões que, na edificação da cidadania moderna, caracterizaram a relação do binômio igualdade/ diferença æ tensões tematizadas de forma parcial no debate contemporâneo.

Palavras-chave: Concepções de cidadania; igualdade; universalismo e diferença.

\section{CITIZENSHIP, EQUALITY AND DIFFERENCE}

The article is concerned with a specific point of recent trends of change in citizenship: the progress of difference and a strong regression of equality. It makes an analysis of the traditional conception of citizenship, the forces that have turned it unstable, the theoretical reaction to it and, above all, the distinct tensions that have historically marked the relation between equality and difference, which have only partially been tackled in contemporary debate.

Keywords: Conceptions of citizenship; equality; universalism and difference. 